\title{
ANN modelling approach for predicting SCC properties - Research considering Algerian experience. Part III. Effect of mineral admixtures
}

\author{
Sahraoui M*, Bouziani T
}

Structures Rehabilitation and Materials Laboratory (SREML), University Amar Telidji, Laghouat, Algeria.

* Corresponding Author: med.sahraoui@lagh-univ.dz

Received: 23-01-2021

Accepted: 02-11-2021

\begin{abstract}
This paper addresses the effect of mineral admixtures on fresh and hardened properties of self compacting concrete (SCC). Artificial neural networks (ANN) and simplex lattice design approach was integrated to predict and evaluate the effect of limestone, marble powder, natural pozzolan and slag on rheological and mechanical properties of SCC evaluated by slump flow, L-Box, V-funnel, sieve segregation test and 28 days compressive strength. The modelling results show an acceptable prediction accuracy of SCC behaviour containing mineral admixtures as substitution of cement especially related to the flow time measured with the $\mathrm{V}$-funnel test and mechanical compressive strength at 28 days.
\end{abstract}

Key words: SCC, ANN, simplex lattice design, mineral admixtures, fresh and hardened properties.

\section{Introduction}

Self-compacting concrete (SCC) is an innovative material characterized by its ability to consolidate without the necessity of mechanical vibration. This advanced concrete should have a low yield stress and moderate viscosity in order to achieve self-compactness and provide high flowability without any segregation between coarse aggregate and mortar (Okamura and Ouchi, 2003; Elemam et al., 2020).

It is generally known that workability and segregation resistance can be achieved by reducing coarse aggregate content, minimizing water to binder ratio while increasing the superplasticizer concentration. Furthermore, the employment of mineral admixtures was considered as another key factors to offer a high paste volume, forming a lubricating layer and achieve more workability (Sahraoui and Bouziani, 2019; Abendeh and Baker, 2021).

A number of studies have been performed to investigate the rheological and mechanical properties of SCC with different mineral admixtures. Daoud and Mahgoub (2020) show that limestone powder can be effectively used as partial replacement of cement to enhance the performance of SCC in fresh and hardened stages. Alyamac et al (2017) confirm the improvement of fresh properties of SCC with the addition of marble powder and after an optimum value of substitution, the compressive strength decreases. Ghafoori et al (2016) show an improvement in SCC fresh properties with incorporation of natural pozzolan while compressive strength is slightly decreased. Zhao et al (2015) reported that the use of slag as mineral admixture in the SCC had not obvious effect on flowability and stability, while a reduction in mechanical properties was observed.

The multilayer perceptron is an artificial neural network technique which can be used to predict SCC properties on the basis of input data extracted from literature. This type of network showed an excellent capability to predict fresh and hardened properties of SCC with high accuracy(Özgür Deneme, 2020; Nguyen et al., 2020). 
Based on Scheffe's simplex lattice design technique, many researches were carried out the development of mathematical models in order to predict and provide a better description in the field of concrete materials (Ubachukwu and Okafor, 2020; Okere and Sule, 2019; Arimanwa et al., 2019). This kind of space-filling design is a symmetrical arrangement of points within the experimental region in a suitable polynomial equation representing the response surface in triangular contour plot (Oba and Amadi, 2020).

\section{Methodology}

The objective of this part is to illustrate the effect of mineral admixtures (limestone, marble powder, pozzolan and slag) as substitution of cement. Based on the design of experiments technique, a simplex-lattice mixture design with three factors and five levels was used to evaluate the effect of the above selected mineral admixtures on fresh and hardened properties of SCC models developed in the Part I (Sahraoui and Bouziani, 2020). The simplex-lattice modelling approaches can describe the influence of mineral admixtures as well as all their possible combinations with cement in binary and ternary systems. The number of experiments is expressed by the flowing relation:

$C=\frac{(\mathrm{m}+q-1) !}{m !(q-1) !}$

Where, $m$ and $q$ are the number of levels and factors respectively. According the Equation (1), the number of combinations to be treated is 21 (with $m=5$ and $q=3$ ). As illustrated in Figure $1, A_{1}$ and $\mathrm{A}_{2}$ present two out of four mineral admixtures (Lim, MP, Pz and Slag) selected in this modelling. While cement remains unchanged in all triangular grid. It should be noted that the developed model is appropriate to predict SCC properties with fixed proportions summarized in Table 1.

The developed model concerning the effect of mineral admixtures is expressed by a secondorder polynomial as follows:

$$
\begin{aligned}
& Y=b_{1} \times \mathrm{Cm}+b_{2} \times \mathrm{Lim}+b_{3} \times \mathrm{MP}+b_{4} \times \mathrm{Slag}+b_{5} \times \mathrm{Pz}+b_{6} \times(\mathrm{Cm} \cdot \mathrm{Lim})+b_{7} \times \\
& (\mathrm{Cm} \cdot \mathrm{MP})+b_{8} \times(\mathrm{Cm} \cdot \mathrm{Slag})+b_{9} \times(\mathrm{Cm} \cdot \mathrm{Pz})+b_{10} \times(\mathrm{Lim} \cdot \mathrm{MP})+b_{11} \times \\
& (\mathrm{Lim} \cdot \mathrm{Slag})+b_{12} \times(\mathrm{Lim} \cdot \mathrm{Pz})+b_{13} \times(\mathrm{MP} \cdot \mathrm{Slag})+b_{14} \times(\mathrm{MP} \cdot \mathrm{Pz})+b_{15} \times
\end{aligned}
$$

$($ Slag $\cdot P z)$

Where $\mathrm{Y}$ is the output result of ANN-based model developed in the first part (Sahraoui and Bouziani, 2020). 
Table 1: Concrete mixture proportioning

\begin{tabular}{|c|c|c|c|c|c|c|}
\hline $\begin{array}{c}\text { Sand } \\
\left(\mathrm{kg} / \mathrm{m}^{3}\right)\end{array}$ & $\begin{array}{c}\text { Gravel 3/8 } \\
\left(\mathrm{kg} / \mathrm{m}^{3}\right)\end{array}$ & $\begin{array}{c}\text { Gravel 8/15 } \\
\left(\mathrm{kg} / \mathrm{m}^{3}\right)\end{array}$ & $\begin{array}{c}\text { Cement } \\
\left(\mathrm{kg} / \mathrm{m}^{3}\right)\end{array}$ & $\begin{array}{c}\text { Lim - MP - Pz - Slag } \\
\left(\mathrm{kg} / \mathrm{m}^{3}\right)\end{array}$ & $\mathrm{W} / \mathrm{b}$ & Sp (\%) \\
\hline \hline 860 & 420 & 420 & $225-450$ & $0-225$ & 0.4 & 1 \\
\hline
\end{tabular}

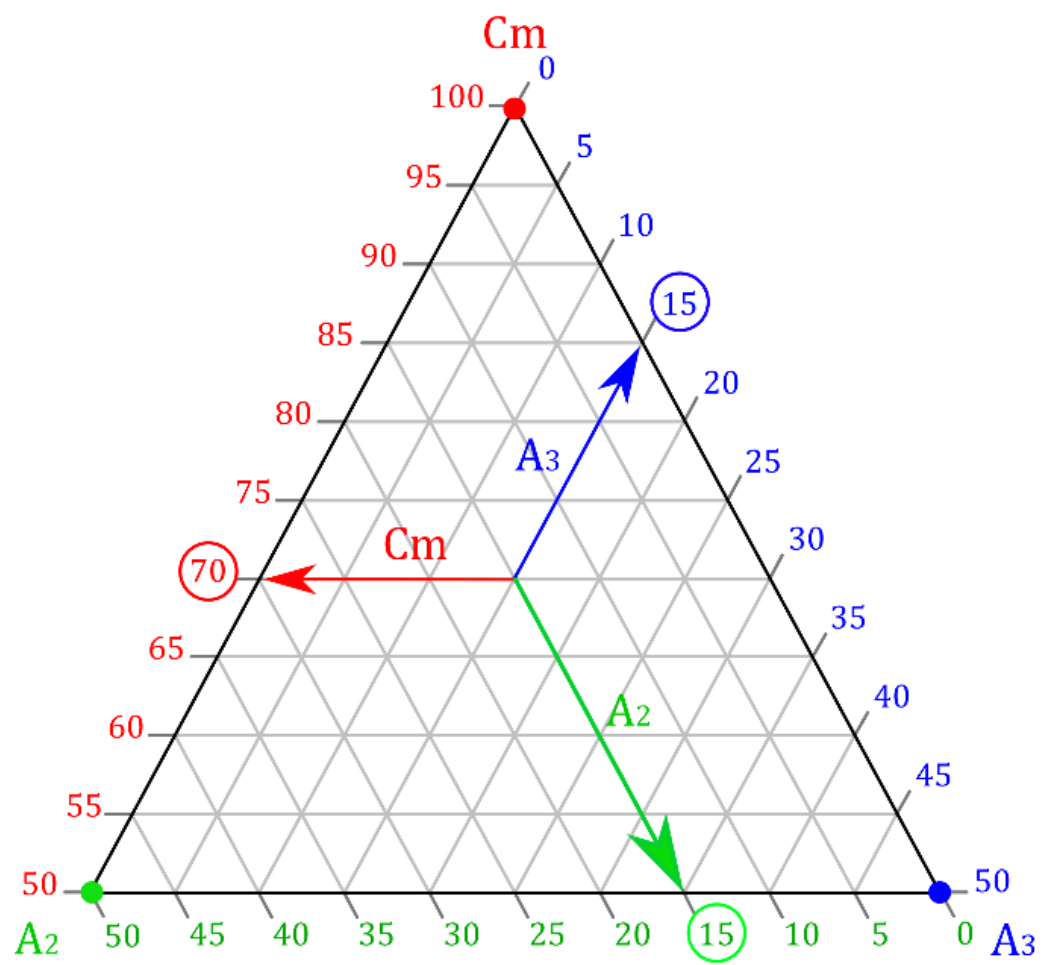

Fig. 1. Illustration of the simplex-lattice design with three factors

\section{Results and discussion}

Mineral admixtures combinations and their output results of ANN models are given in Table 2 and the estimated modelling parameters of all responses are summarized in Table 3.

$\mathrm{V}$-funnel derived models have the stronger R-square and the lower root mean square error $\left(\mathrm{R}^{2}=0.99\right.$ and RMSE in the range of $\left.0.2-0.25\right)$ which indicate the good prediction performance of $\mathrm{V}$-funnel models in this ANN modelling compared to the other test results.

L-box derived model developed with MP and Slag has the highest RMSE value compared to the other models which mean that L-box derived model has a low accuracy in predicting SCC passing ability in this case study. It is also noted that slump flow model developed with Lim and Slag exhibit a low $\mathrm{R}^{2}$ and high RMSE compared to that with MP and Pz.

The $\mathrm{p}$-value lower than $0.05(\mathrm{p}<0.0001)$ indicates that developed models are accurate and performed satisfactorily to predict SCC properties. It is worth bearing in mind that ternary graphs selected in this work are chosen according to high and low values of obtained models in order to better insights the effect of mineral admixtures. 
Table 2: Mineral admixtures combinations and output results of ANN models

\begin{tabular}{|c|c|c|c|c|c|c|c|c|c|c|c|c|c|}
\hline \multirow{2}{*}{$\begin{array}{l}\stackrel{o}{z}_{x} \\
\stackrel{x}{\Sigma}\end{array}$} & \multicolumn{3}{|c|}{$\begin{array}{c}\text { MA } \\
\text { combinations }\end{array}$} & \multicolumn{2}{|c|}{ Slump (cm) } & \multicolumn{2}{|c|}{ L-Box (\%) } & \multicolumn{2}{|c|}{ V-Funnel (s) } & \multicolumn{2}{|c|}{ Pi (\%) } & \multicolumn{2}{|c|}{ Rc28 (MPa) } \\
\hline & $\mathrm{Cm}$ & $\mathrm{A}_{2}$ & $\mathrm{~A}_{3}$ & $2: \operatorname{Lim}$ & & $2:$ Lim & MP & & $\underline{\mathrm{A}_{2}: \mathrm{Lim}}$ & $: \mathrm{MP}$ & 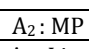 & :Lim & $\mathrm{A}_{2}: \operatorname{Lim}$ \\
\hline & & RL & & & & & & & & & & & \\
\hline 1 & & 0 & & & & & & & & & & & \\
\hline 2 & & 0,2 & 8 & & & 6,53 & & 7,91 & 4,4 & 77 & 7 & 5,93 & 16 \\
\hline 3 & $c$ & 4 & & 6,18 & 7,05 & 97,34 & 3,99 & 6,99 & 4,98 & 8,26 & 2,32 & 50,65 & 24,52 \\
\hline 4 & 0 & 0,6 & , & 76,31 & 3,93 & 85,01 &,, 10 & 5,61 & 7,5 &, 77 & 2,76 & 0,62 & 2,55 \\
\hline 5 & & 8 & & 70,82 & & 79,46 & & & & ,15 & & 1 & 8,11 \\
\hline 0 & 0 & 1 & 0 & 72 & , ,88 & 66,87 & 2,52 & 2,06 & 16,02 & 8,24 & 8,24 & 3,41 & 3,41 \\
\hline 7 & & U & & 4,02 & 43 & 93,08 & 5,14 & 5,56 & 5,06 & 7,48 & 11,02 & 7,06 & 44,99 \\
\hline 8 & & 0,2 & & 68,98 & & 1 & & & & 52 & 25 & 13 & $\overline{0,82}$ \\
\hline 9 & & 0,4 & & , 90 &, 93 & 97,24 & 3,20 & 3,69 & 5,96 & 7,87 & 3,01 & 0,02 & 31,22 \\
\hline 10 & 0,2 & 6 & ( & ,88 & 35 & 82,58 & 5,63 & 37 & 9,01 & 5,47 & 0,08 & 7,12 & 34,49 \\
\hline 11 & 0,2 & 0,8 & ( & 72,63 & 8,22 & 81,32 & 73,62 & 0,95 & 13,1 & 3,34 & 8, & 4,28 & 54,28 \\
\hline 12 & 0, & & 0,6 & 64,51 & 90 & 88,94 & 4,08 & 12,69 & 5,12 & 8,26 & 2,12 & 51,67 & 46,21 \\
\hline 13 & 0,4 & 0,2 & & 53 & 21 & 92,66 & 34 & ,64 & 5,13 & 9,06 & 3,03 & 58,09 & 4,81 \\
\hline 14 & 0,4 & 0,4 & 0,2 & 88,49 & 1,21 & 96,85 & 9,55 & 0,53 & 6,8 & 7,77 & 13,02 & 68,63 & 44,25 \\
\hline 15 & 0,4 & 0,6 & ( & 83,48 & 66 & 81,59 & 80,86 & 945 & 10,17 & 8,50 & 8,50 & 58,75 & 58,75 \\
\hline 16 & 0,6 & 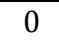 & 0 & 68,16 & ,30 & 83,60 & 0,59 & 95 & 5,35 & 8,99 & 12,98 & 66,29 & 49,50 \\
\hline 1 & 0,6 & 0,2 & 0,2 & 86,81 & 71,83 & 93,15 & 53,00 & 3,78 & 5,61 & 10,38 & 13,48 & 56,13 & 51,80 \\
\hline 18 & 0,6 & 0,4 & 0 & & 71 & 85,58 & 57 & 7,82 & $7,5 \mathrm{c}$ & 01 & 9,61 & 3,38 & 73,38 \\
\hline 19 & 0,8 & 0 & 0,2 & 74,35 & 72,13 & 79,86 & 70,65 & 7,64 & 5,67 & 10,75 & 13,52 & 67,52 & 59,62 \\
\hline 20 & 0,8 & , & 0 & & & & & & & 94 & 2,94 & 9,98 & 9,98 \\
\hline 21 & 1 & 0 & 0 & 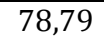 & Fi & 83,45 & 83,45 & 6,01 & 6,01 & 13,78 & 13,78 & 79,96 & 9,96 \\
\hline
\end{tabular}

Table 3: Model parameters estimates of modelling output results

\begin{tabular}{|c|c|c|c|c|c|c|c|c|c|c|}
\hline & \multicolumn{2}{|c|}{ Slump $(\mathrm{cm})$} & \multicolumn{2}{|c|}{ L-box $(\%)$} & \multicolumn{2}{|c|}{ V-funnel (s) } & \multicolumn{2}{|c|}{ Pi (\%) } & \multicolumn{2}{|c|}{$\mathrm{Rc} 28(\mathrm{MPa})$} \\
\hline & $\begin{array}{l}\mathrm{A}_{2}: \\
\mathrm{Lim}\end{array}$ & $\mathrm{A}_{2}: \mathrm{MP}$ & $\begin{array}{l}\mathrm{A}_{2}: \\
\mathrm{Lim}\end{array}$ & $\mathrm{A}_{2}: \mathrm{MP}$ & $\mathrm{A}_{2}: \mathrm{Pz}$ & $\mathrm{A}_{2}: \mathrm{Lim}$ & $\mathrm{A}_{2}: \mathrm{MP}$ & $\mathrm{A}_{2}: \mathrm{MP}$ & $\begin{array}{l}\mathrm{A}_{2}: \\
\mathrm{Lim}\end{array}$ & $\mathrm{A}_{2}: \mathrm{Lim}$ \\
\hline & $\begin{array}{l}\mathrm{A}_{3}: \\
\text { Slag }\end{array}$ & $\mathrm{A}_{3}: \mathrm{Pz}$ & $\mathrm{A}_{3}: \mathrm{Pz}$ & $\begin{array}{l}\mathrm{A}_{3}: \\
\text { Slag }\end{array}$ & $\begin{array}{l}\mathrm{A}_{3}: \\
\text { Slag }\end{array}$ & $\mathrm{A}_{3}: \mathrm{MP}$ & $\mathrm{A}_{3}: \mathrm{Pz}$ & $\begin{array}{l}\mathrm{A}_{3}: \\
\mathrm{Lim}\end{array}$ & $\mathrm{A}_{3}: \mathrm{MP}$ & $\mathrm{A}_{3}: \mathrm{Pz}$ \\
\hline $\mathrm{R}^{2}$ & 0.85 & 0.96 & 0.83 & 0.87 & 0.99 & 0.99 & 0.80 & 0.83 & 0.93 & 0.95 \\
\hline RMSE & 3.93 & 1.83 & 3.89 & 8.68 & 0.20 & 0.25 & 1.15 & 0.93 & 3.34 & 4.31 \\
\hline Coeff & & & & & $\mathrm{P}<$ & .0001 & & & & \\
\hline$b_{1}$ & 78,81 & 77,68 & 83,06 & 78,78 & 5,71 & 5,80 & 13,87 & 13,88 & 80,69 & 81,38 \\
\hline$b_{2}$ & 63,02 & - & 65,13 & - & - & - & - & 7,09 & 48,81 & 51,23 \\
\hline$b_{3}$ & - & 65,59 & - & 58,12 & - & 16,82 & 6,85 & 9,58 & 43,27 & - \\
\hline$b_{4}$ & 60,07 & - & - & 83,72 & 12,21 & - & - & - & - & - \\
\hline$b_{5}$ & - & 46,96 & 96,12 & - & 18,53 & 5,01 & 7,90 & - & - & 48,20 \\
\hline$b_{6}$ & 68,57 & - & 60,41 & - & - & - & - & $-1,97$ & 15,75 & $-7,05$ \\
\hline$b_{7}$ & - & 9,73 & - & 33,70 & - & $-9,88$ & $-3,57$ & 5,07 & $-27,71$ & - \\
\hline$b_{8}$ & $-3,07$ & - & - & $-10,79$ & $-1,63$ & - & - & - & - & - \\
\hline$b_{9}$ & - & 22,89 & $-9,12$ & - & $-3,53$ & $-0,71$ & $-8,12$ & - & - & $-71,64$ \\
\hline$b_{10}$ & - & - & - & - & - & - & - & 15,85 & 22,60 & - \\
\hline$b_{11}$ & 58,73 & - & - & - & - & - & - & - & - & - \\
\hline$b_{12}$ & - & - & 48,86 & - & - & - & - & - & - & $-103,17$ \\
\hline$b_{13}$ & - & - & - & $-200,87$ & - & - & - & - & - & - \\
\hline$b_{14}$ & - & 20,03 & - & - & - & $-19,03$ & $-3,69$ & - & - & - \\
\hline$b_{15}$ & - & - & - & - & 3,75 & - & - & - & - & - \\
\hline
\end{tabular}




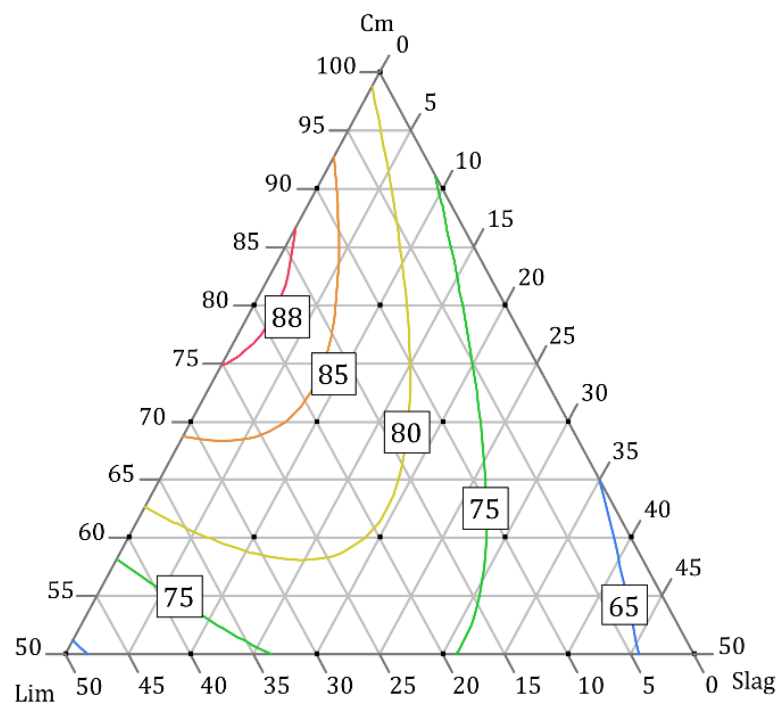

Fig. 2. Ternary plot of slump flow $(\mathrm{cm})$ as function of $\mathrm{Cm}$, Lim and Slag proportions.

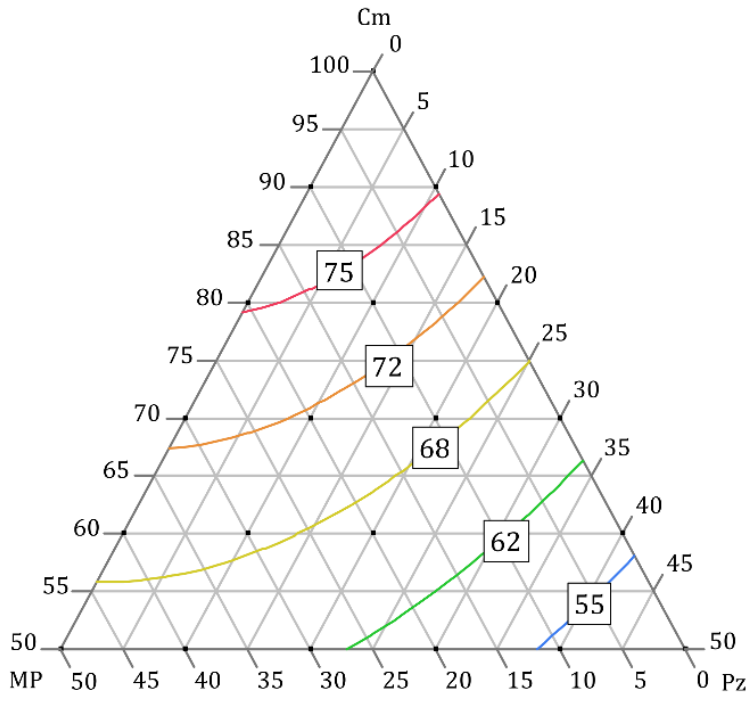

Fig. 3. Ternary plot of slump flow (cm) as function of Cm, MP and Pz proportions.

Ternary contour plots presented in Figure 2 illustrate the effects of cement, limestone and slag proportions on predicting slump flow. From this figure, it can be seen that slump flow increased with the increase of limestone proportions (corresponding to the rate of 15 to $25 \%$ of Lim) and then decreased. This is due to the fact that limestone filler scattered between cement particles, the maximum packing density is achieved and hence larger amount of excess water for more lubrication (Kounakoff et al., 2017; Hanzic and Ho, 2017; Ren et al., 2020). Once the space between cement grains is filled, limestone filler began to occupy the place of cement particles which leads to an increase in specific surface area and hence more effective water for lubrication. Therefore, the mixture becomes sticky, denser and hence less self-comparable (Benabed et al., 2012; Daoud and Mahgoub, 2020).

Figure 2 indicates that the increase in slag results in a reduction of slump flow. Results in literature revealed that the addition of slag powder has reasonably enhanced the flowability (Pyo and Kim, 2017; Liu et al., 2018; Gopinathan and Anand, 2018). In this case study, the decrease in flowability may be attributed to the fact that the mixtures models were designed at fixed water and superplasticizer dosage. Slag has a reactive character and requires more water and superplasticizer than almost other inert additions such as limestone filler, moreover, some superplasticizer molecules can be absorbed to the surface of very fine particles slag and leads to a higher request to superplasticizer (Brahim, 2018; Salehi and Mazloom, 2019) . It should be noted that only three studies were intended to study the effect of slag powder behaviour in this study (representing 7 of all 167 mixtures collected from literature) and this could make the model lacks to evaluate the effect of slag compared to the other mineral admixtures. This is also confirmed by high RMSE (3.93) and low $\mathrm{R}^{2}$ (0.85) compared to L-box model parameters developed with MP and Pz, as shown in Table 3.

The effect of $\mathrm{Cm}, \mathrm{MP}$ and $\mathrm{Pz}$ on slump flow is plotted in Figure 3. It was observed the same impact of marble powder as limestone on flowability but the optimum substitution is not clearly shown. This might be explained by the increases in paste volume and cohesiveness of SCC mixture caused by the lower density of marble powder. The increase in flowability with the 
increase in MP is due also to its pore-filling effect (Boukhelkhal et al., 2016; Praveenkumar et al., 2017).

It can be also seen that the increase of Pz proportion leads to a decrease in slump flow diameter and mixtures made with high content of $\mathrm{Pz}$ exhibit the lowest flowability, this phenomenon is attributed to the higher water demand of Pz particles in order to achieve a suitable workability (Menadi and Kenai, 2018). This is in agreement with the findings of other researchers (Belaidi et al., 2012; Omrane et al., 2017; Ahmad et al., 2019).

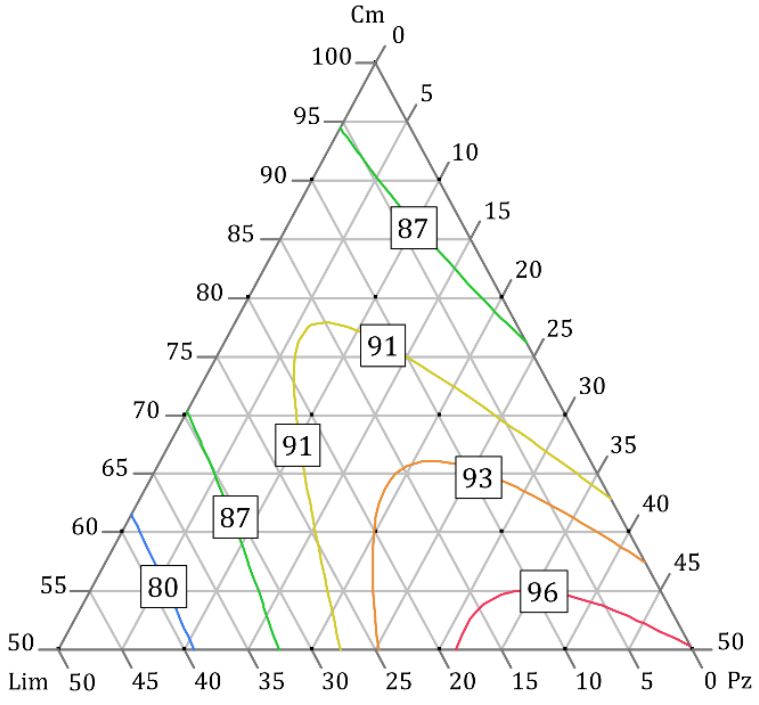

Fig.4. Ternary plot of L-Box ratio (\%) as function of Cm, Lim and Pz proportions.

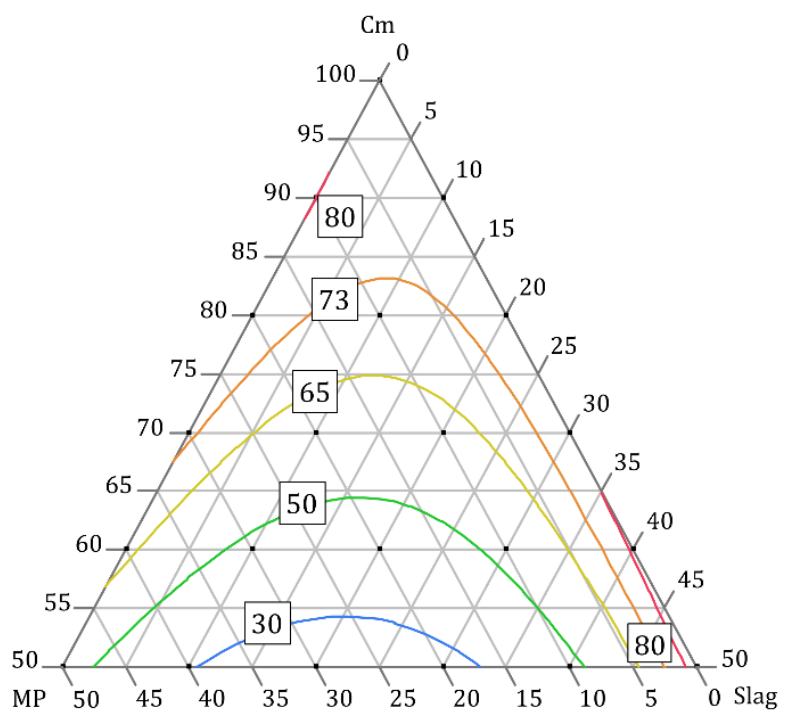

Fig. 5. Ternary plot of L-Box ratio (\%) as function of Cm, MP and Slag proportions.

Ternary contour graph illustrated in Figure 4 presents the effects of Lim and Pz proportions on the L-Box ratio. It is evident that L-Box ratio increases to a maximum value with $10-15 \%$ of Lim. The replacement of cement by limestone filler will broaden the particle size distribution and filling up the interstitial void that increases wet packing density of mixture and therefore the maximum passing ability increases (Lai et al., 2019). It can be also seen from figure 4 that while the Pz content increases, the L-Box ratio increases. This may be explained by the fact that all modelling concrete mixtures were designed at fixed SP dosage, resulting in $\mathrm{Pz}$ contained mixtures to have better viscosity and consequently the passing ability increased (Ghafoori et al., 2016).

The Variations in L-Box ratios, with respect to $\mathrm{Cm}$, MP and Slag variations are given in Figure 5. The acceptable values of passing ability according to EFNARC guideline was with $10 \%$ of MP in binary systems Cm-MP and more $35 \%$ of slag in Cm-Slag binary systems, beyond these combinations, L-box ratios are less than $80 \%$ which is out the range prescribed (EFNARC, 2002).

MP particles provide better filling effect to increase packing density, resulting in a slower horizontal flow in the L-box and therefore a low passing ability (Alyousef et al., 2019). Beyond this optimum, L-Box ratio decreases with the increase in MP contents in binary and ternary systems. The large amount of MP result in a high paste volume, while exhibiting a decrease in the viscosity of SCC mixture (Alyousef et al., 2018). It is remarkable from Figure 5 that the amount of slag proportion does not appear to have a significant effect on predicting L-Box ratio in binary system Cm-Slag, which is confirmed by the highest RMSE value (8.68) as mentioned in Table 3. 


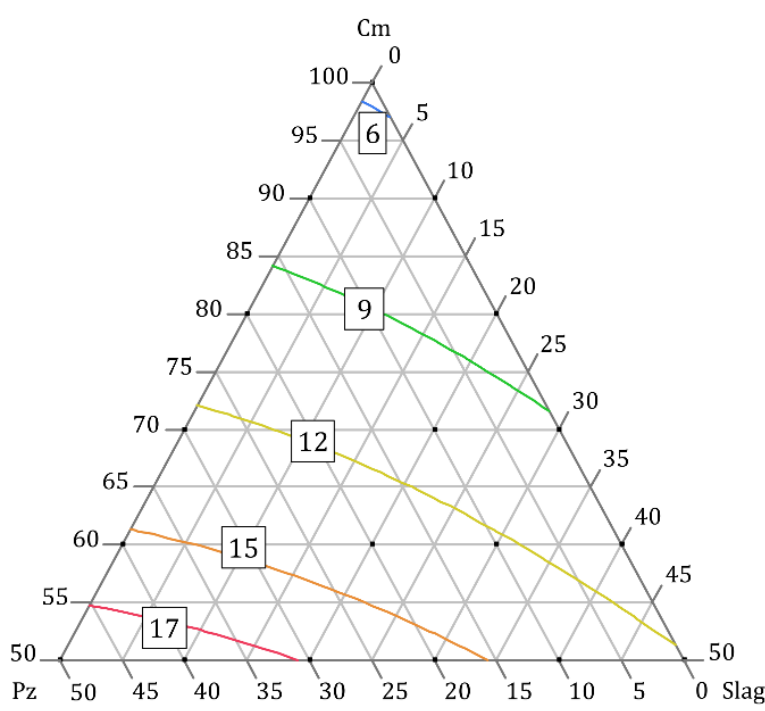

Fig. 6. Ternary plot of $V$-funnel time (s) as function of $\mathrm{Cm}, \mathrm{Pz}$ and Slag proportions.

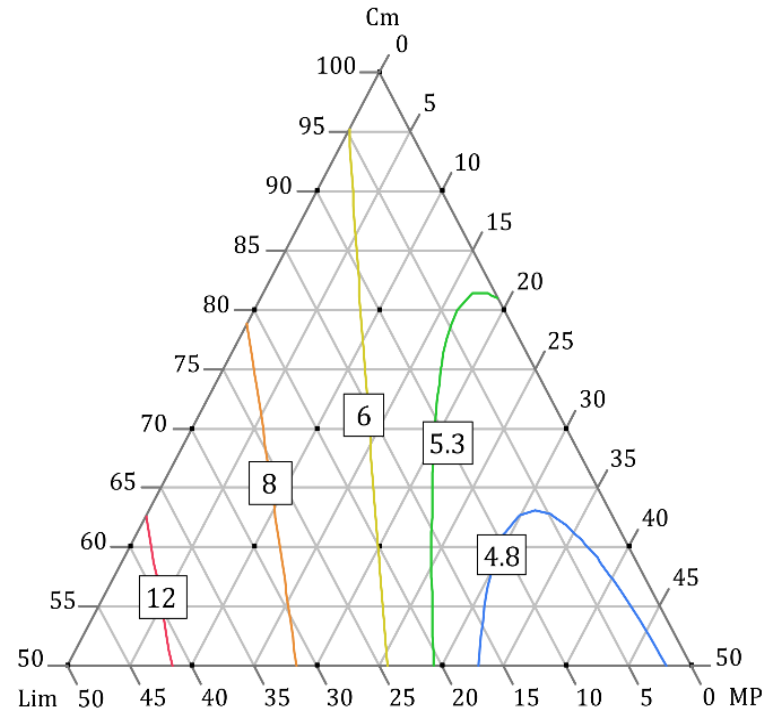

Fig. 7. Ternary plot of $\mathrm{V}$-funnel time (s) as function of $\mathrm{Cm}$, Lim and MP proportions.

The effect of $\mathrm{Pz}$ and Slag proportions on the flow time of $\mathrm{V}$-funnel is illustrated in Figure 6 , all Vfunnel measurements are in the recommended range (EFNARC, 2002). As seen in this figure, the flow time increases with increasing Pz and Slag content. Adjoudj et al (2014) show an increase the viscosity when using high levels of natural pozzolan and blast furnace slag. These results are further confirmed by other researchers (Salhi et al., 2020; Yahiaoui et al., 2017; Belaidi et al., 2012; Boukendakdji et al., 2009).

Figure 7 presents the variation of V-funnel time as a function of limestone and marble powder content. From the obtained results, it can be seen that Limestone leads to an increase in flow time of V-funnel while the effect of MP is inconspicuous in this case. This can be explained by the effect of limestone on the enhancement of viscosity, as a result of its contribution in modifying the grading of the solid particles in mixture suspension and modified the water quantity available for the hydration process (Ede et al., 2019; Youness et al., 2020). Similar results were also reported by other researchers (Benabed et al., 2012; Babikir and Ahmed, 2020; Daoud and Mahgoub, 2020).

Ternary contour plots showing in Figures 8 and 9 illustrate the variations of static stability with respect to MP, Pz and Lim proportions. Results show that Pi values decreased with the increase of MP, Pz and Lim in binary and ternary combinations. Tennich et al (2015) and Hameed et al (2016) show that the segregation resistance was increased with the increase in MP contents and the viscosity becomes satisfactory. Limestone filler provides large specific surface area accessible to unit volume of water due to its small particle size, which helps to reduce segregation and bleeding (Li et al., 2018). Menadi and Kenai (2018) found that SCC mixtures containing $\mathrm{Pz}$ with weight substitution level of 10 or $15 \%$ satisfy the fresh-state behaviour requirements related to high segregation resistance. 


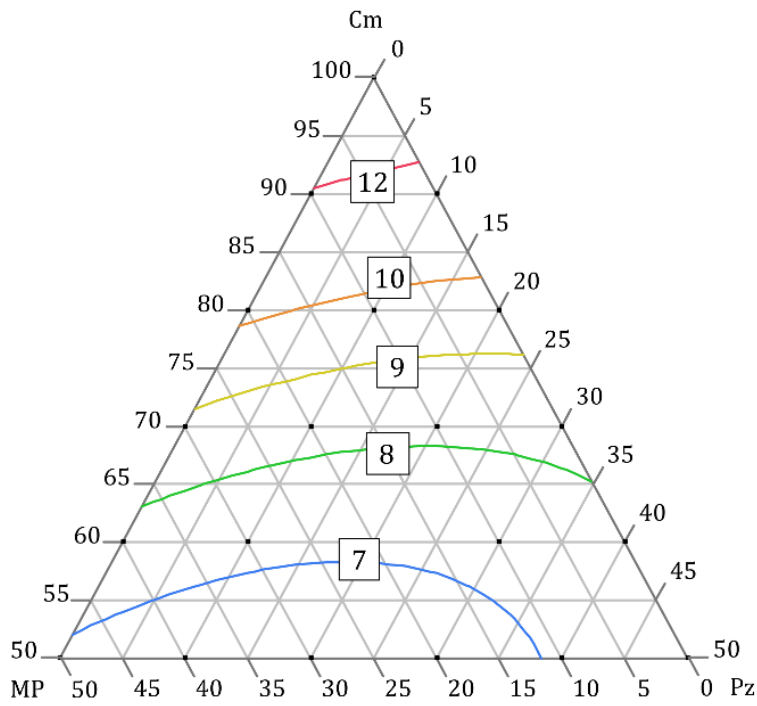

Fig. 8. Ternary plot of sieve stability $\mathrm{Pi}(\%)$ as function of $\mathrm{Cm}$, MP and Pz proportions.

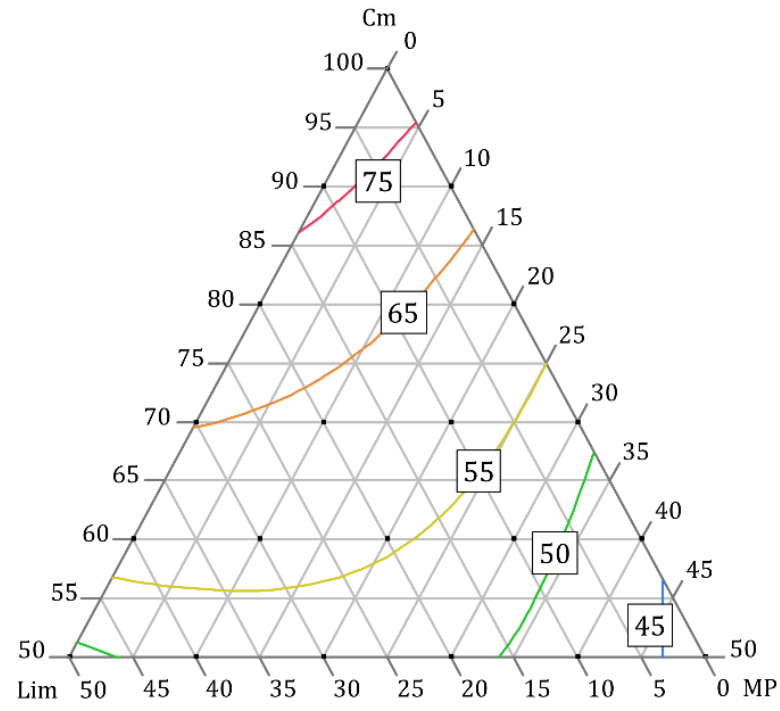

Fig. 10. Ternary plot of Rc28 (MPa) as function of Cm, Lim and MP proportions.

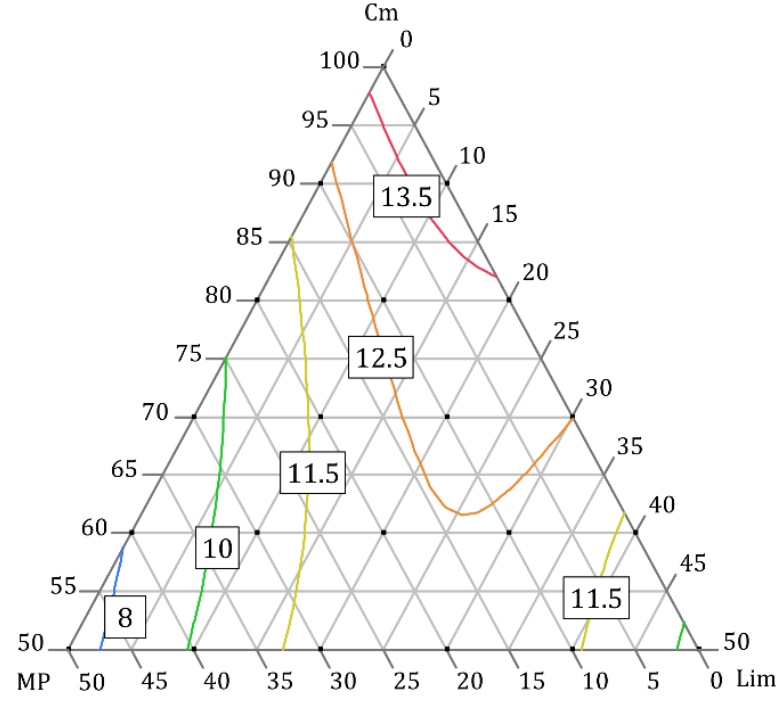

Fig. 9. Ternary plot of sieve stability Pi (\%) as function of $\mathrm{Cm}$, MP and Lim proportions.

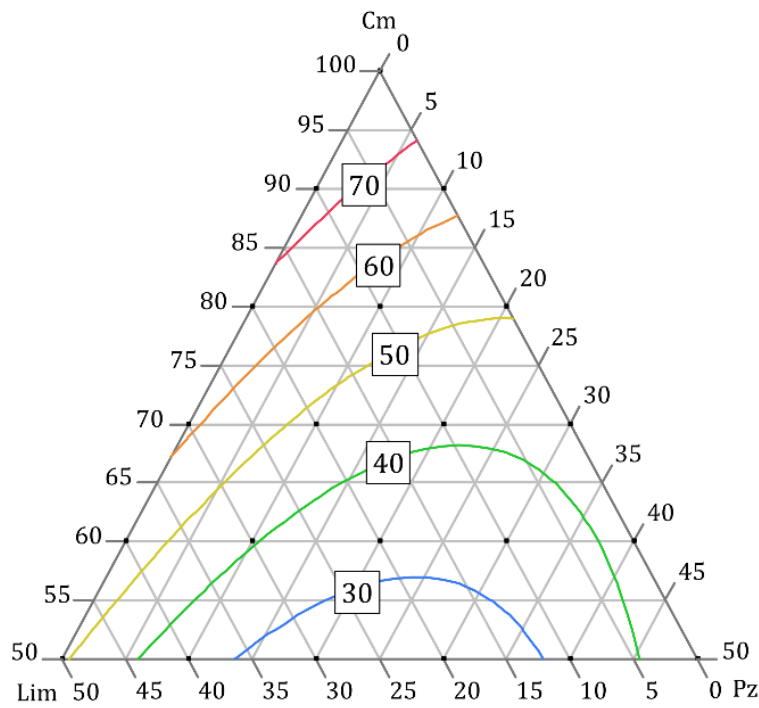

Fig. 11. Ternary plot of Rc28 (MPa) as function of Cm, Lim and Pz proportions.

In Figures 10 and 11, compressive strength at 28 days of SCC made with all possible binary and ternary combinations of $\mathrm{Cm}$, Lim, MP and $\mathrm{Pz}$ were plotted. It is clear that the increase in Lim, MP and $\mathrm{Pz}$ contents decrease the compressive strength at 28 days. A partial replacement of cement by limestone filler causes a decrease in clinker content, and therefore the decrease of 28-day compressive strength (Akbar, 2014; Ayat et al., 2018). The slower evolution of strength at 28 days shown in Figure 11 also caused by the slow pozzolanic reaction of $\mathrm{PZ}$ compared to $\mathrm{C}_{3} \mathrm{~S}$ hydration of ordinary Portland cement (Senhadji et al., 2012; Belaidi et al., 2012).

\section{Conclusion}

In this paper, ANNs were developed to predict the effect of mineral admixtures on fresh and hardened properties of SCC considering Algerian experience. Following conclusions based on experimental results can be listed as below: 
- A high flowability was observed for SCC mixtures containing $15-25 \%$ of limestone filler as partial substitution of cement.

- L-Box ratio increases to a maximum value with $10-15 \%$ of Lim and high Pz contents.

- An acceptable passing ability remains within the limits prescribed by EFNARC can be obtained with $10 \%$ of MP and up to $35 \%$ of slag in Cm-MP and Cm-Slag binary systems respectively.

- The time of flow measured with V-Funnel test increased with increasing Pz and Slag contents.

- Static segregation decreased with the increase of Lim, MP and Pz and all studied modelling mixtures proves the standard condition prescribed by AFGC recommendations (Pi index lower than 15\%).

- A reduction in mechanical compressive strength with increasing Lim, MP and $\mathrm{Pz}$ contents for all possible binary and ternary combinations.

\section{References}

Abendeh, R. M., \& Bani Baker, M. (2021). Using steel slag aggregate to strengthen self-compacting concrete durability. Proceedings of the Institution of Civil Engineers-Structures and Buildings, 1-15.

Ahmad, S., Mohaisen, K. O., Adekunle, S. K., Al-Dulaijan, S. U., \& Maslehuddin, M. (2019). Influence of admixing natural pozzolan as partial replacement of cement and microsilica in UHPC mixtures. Construction and Building Materials, 198, 437-444.

Akbar, Ramezanianpour Ali. (2014). Cement Replacement Materials: Properties, Durability, Sustainability. Springer Geochemistry/Mineralogy

Alyamac, K. E., Ghafari, E., \& Ince, R. (2017). Development of eco-efficient self-compacting concrete with waste marble powder using the response surface method. Journal of Cleaner Production, 144, 192202.

Alyousef, R., Benjeddou, O., Khadimallah, M. A., Mohamed, A. M., \& Soussi, C. (2018). Study of the effects of marble powder amount on the self-compacting concretes properties by microstructure analysis on cement-marble powder pastes. Advances in Civil Engineering, 2018.

Alyousef, R., Benjeddou, O., Soussi, C., Khadimallah, M. A., \& Mustafa Mohamed, A. (2019). Effects of incorporation of marble powder obtained by recycling waste sludge and limestone powder on rheology, compressive strength, and durability of self-compacting concrete. Advances in Materials Science and Engineering.

Arimanwa, J. I., Onwuka, D. O., Arimanwa, M. C., \& Ajoku, C. A. (2019). Simplex lattice design models for the determination of modulus of rupture of concretes. Nigerian Journal of Technological Development, 16(4), 213-219.

Ayat, H., Kellouche, Y., Ghrici, M., \& Boukhatem, B. (2018). Compressive strength prediction of limestone filler concrete using artificial neural networks. Adv. Comput. Des, 3(3), 289-302.

Babikir, K. S. E., \& Ahmed, Y. H. (2020). Proportioning Self Compacting Concrete in Hot Weather Utilizing Limestone Powder. Journal of Cement Based Composites, 1, 6-10.

Belaidi, A. S. E., Azzouz, L., Kadri, E., \& Kenai, S. (2012). Effect of natural pozzolana and marble powder on the properties of self-compacting concrete. Construction and Building Materials, 31, 251-257. 
Benabed, B., Kadri, E. H., Azzouz, L., \& Kenai, S. (2012). Properties of self-compacting mortar made with various types of sand. Cement and Concrete Composites, 34(10), 1167-1173.

Boukendakdji, O., Kenai, S., Kadri, E. H., \& Rouis, F. (2009). Effect of slag on the rheology of fresh selfcompacted concrete. Construction and Building Materials, 23(7), 2593-2598.

Boukhelkhal, A., Azzouz, L., Belaïdi, A. S. E., \& Benabed, B. (2016). Effects of marble powder as a partial replacement of cement on some engineering properties of self-compacting concrete. Journal of adhesion science and Technology, 30(22), 2405-2419.

Brahim, Nécira. (2018). Développement des bétons autoplaçants à hautes performances: influence de la composition, Doctoral dissertation, University Mohamed Khider Biskra, Algeria.

Daoud, O. M. A., \& Mahgoub, O. S. (2020). Effect of limestone powder on self-compacting concrete. FES Journal of Engineering Sciences, 9(2), 71-78.

Ede, A. N., Oshogbunu, O. B. A. T. A. R. H. I. E., Olofinnade, O. M., Jolayemi, J., Oyebisi, S. O., Mark, G., \& Awoyera, P. O. (2019). Effects of bamboo fibers and limestone powder on fresh properties of selfcompacting concrete, MAT42, 1-6.

EFNARC, (2002). Specification. Guidelines for Self-Compacting Concrete, London, UK: Association House $32, \mathrm{p} 34$.

Elemam, W. E., Abdelraheem, A. H., Mahdy, M. G., \& Tahwia, A. M. (2020). Optimizing fresh properties and compressive strength of self-consolidating concrete. Construction and Building Materials, 249, 118781..

Ghafoori, N., Sharbaf, M., Najimi, M., \& Batilov, I. (2016). Natural pozzolan contained Self-Consolidating Concrete, Fourth International Conference on Sustainable Construction Materials and Technologies, Las Vegas, USA.

Gopinathan, S., \& Anand, K. B. (2018). Properties of cement grout modified with ultra-fine slag. Frontiers of Structural and Civil Engineering, 12(1), 58-66.

Hanzic, L., \& Ho, J. C. M. (2017). Multi-sized fillers to improve strength and flowability of concrete. Advances in Cement Research, 29(3), 112-124.

Kounakoff, B. A., Hanzic, L., \& Ho, J. C. M. (2017). Limestone and silica fume to improve concurrent flowability-segregation limits of concrete. Magazine of Concrete Research, 69(23), 1189-1202.

Lai, M., Hanzic, L., \& Ho, J. C. (2019). Fillers to improve passing ability of concrete. Structural Concrete, 20(1), 185-197.

Li, C., Jiang, L., Xu, N., \& Jiang, S. (2018). Pore structure and permeability of concrete with high volume of limestone powder addition. Powder Technology, 338, 416-424.

Liu, Z., El-Tawil, S., Hansen, W., \& Wang, F. (2018). Effect of slag cement on the properties of ultra-high performance concrete. Construction and Building Materials, 190, 830-837.

Menadi, B., \& Kenai, S. (2018). Influence of natural pozzolana content on self-compacting concrete durability properties. In IOP Conference Series: Materials Science and Engineering,. 431, 10, 102011, IOP Publishing.

Nguyen, C. H., Tran, L. H., \& Ho, K. N. (2020). Application of neural network to predict the workability parameters of self-compacting concrete. In CIGOS 2019, Innovation for Sustainable Infrastructure (pp. 1161-1166). Springer, Singapore.

Oba, K. M., \& Amadi, I. G. (2020). A predictive mathematical model for water absorption of sawdust ashSand concrete. International Journal of Engineering and Management Research, 10. 
Okamura, H., \& Ouchi, M. (2003). Self-compacting concrete. Journal of advanced concrete technology, 1(1), 5-15.

Okere, C. E., and S. Sule. (2019). Cost Optimization of Chikoko-Cement Concrete Using Scheffe's Polynomial Function, International Journal of Recent Engineering Science, 6 (3), 1-9.

Omrane, M., Kenai, S., Kadri, E. H., \& Aït-Mokhtar, A. (2017). Performance and durability of self-compacting concrete using recycled concrete aggregates and natural pozzolan. Journal of Cleaner Production, $165,415-430$.

Özgür Deneme, İ. (2020). Modelling of compressive strength of self-compacting concrete containing fly ash by gene expression programming. Revista de la construcción, 19(2), 346-358.

Praveenkumar, S., K. Murugesan, and N. Sharan Nikhil. (2017). Influence of Marble Powder and Fly Ash in Fresh and Hardened Properties of Self Compacting Concrete, International Journal of ChemTech Research, 10(8), 314-319.

Pyo, S., \& Kim, H. K. (2017). Fresh and hardened properties of ultra-high performance concrete incorporating coal bottom ash and slag powder. Construction and Building Materials, 131, 459-466.

Ren, Q., Xie, M., Zhu, X., Zhang, Y., \& Jiang, Z. (2020). Role of limestone powder in early-age cement paste considering fineness effects. Journal of Materials in Civil Engineering, 32(10), 04020289.

Sahraoui, M., \& Bouziani, T. (2019). Effects of fine aggregates types and contents on rheological and fresh properties of SCC. Journal of Building Engineering, 26, 100890.

Sahraoui, M., \& Bouziani, T. (2020). ANN modelling approach for predicting SCC properties-Research considering Algerian experience. Part I. Development and analysis of models. Journal of Building Materials and Structures, 7(2), 188.

Salehi, H., \& Mazloom, M. (2019). Opposite effects of ground granulated blast-furnace slag and silica fume on the fracture behavior of self-compacting lightweight concrete. Construction and Building Materials, 222, 622-632.

Salhi, M., Ghrici, M., Bilir, T., \& Uysal, M. (2020). Combined effect of temperature and time on the flow properties of self-compacting concrete. Construction and Building Materials, 240, 117914.

Senhadji, Y., Escadeillas, G., Khelafi, H., Mouli, M., \& Benosman, A. S. (2012). Evaluation of natural pozzolan for use as supplementary cementitious material. European Journal of Environmental and Civil Engineering, 16(1), 77-96.

Ubachukwu, O. A., \& Okafor. F. O. (2020). Formulation of predictive model for the compressive strength of oyster shell powder-cement concrete using Scheffe's simplex lattice theory. Epitoanyag-Journal of Silicate Based \& Composite Materials, 72(6).

Yahiaoui, W., Kenai, S., Menadi, B., \& Kadri, E. H. (2017). Durability of self-compacted concrete containing slag in hot climate. Advances in concrete construction, 5(3), 271.

Youness, D., Mechaymech, A., \& Al Wardany, R. (2021). Flow assessment and development towards sustainable self-consolidating concrete using blended basalt and limestone-cement systems. Journal of Cleaner Production, 283, 124582.

Zhao, H., Sun, W., Wu, X., \& Gao, B. (2015). The properties of the self-compacting concrete with fly ash and ground granulated blast furnace slag mineral admixtures. Journal of Cleaner Production, 95, 66-74. 